\title{
Comparative Assessment of Choline Chloride-based Deep Eutectic Solvents in the Purification of Lumbang (Aleurites moluccana)-derived Biodiesel
}

\section{NELSON R. VILLARANTE ${ }^{1}$, CHELSEA H. IBARRIENTOS ${ }^{1}$ and DERICK ERL P. SUMALAPAO*}

\author{
'Department of Physical Sciences and Mathematics, College of Arts and Sciences, \\ University of the Philippines Manila, Philippines. \\ ${ }^{2}$ Department of Epidemiology and Biostatistics, College of Public Health, \\ University of the Philippines Manila, Philippines. \\ *Corresponding author E-mail: dpsumalapao1@up.edu.ph
}

http://dx.doi.org/10.13005/ojc/360305

(Received: April 19, 2020; Accepted: June 05, 2020)

\begin{abstract}
This research investigation assessed the potential of choline chloride-based deep eutectic solvents (DESs) in removing impurities from lumbang (Aleurites moluccana)-derived biodiesel. Lumbang oil ( $56 \%$ wt.) which contained about $6.5 \%$ free fatty acids was converted into biodiesel through direct acid-base catalyzed reaction. Three different DESs were prepared in a 1:2 (choline chloride:glycerol, ChCl:Gly), 1:2 (choline chloride:ethylene glycol, ChCl:Eg), and 1:2:2 (choline chloride:glycerol:ethylene glycol, $\mathrm{ChCl}: G l y: E g)$ molar ratios. The crude biodiesel was purified with DESs in a 1:1 and 2:1 DES-biodiesel molar ratios. The results of the investigation showed variations in the extraction efficiencies of the three DESs. Binary DESs (DES1 and DES2) successfully fulfilled the standard limits for biodiesel (ASTM D6751; EN 14214) with ChCl:Eg DES (1:2) in a 1:1 DES:biodiesel molar ratio exhibiting maximum removal. Physicochemical characterization of the purified biodiesel showed a decrement in impurities with maximum removal efficiencies of $98.0 \%$ (methanol), $89.0 \%$ (total glycerides ), and $99.9 \%$ (unreacted triglycerides). The decrease in glyceride impurities was reflected in the decrease of kinematic viscosity and enhancement of fatty acid methyl ester. These results demonstrated the effectivity of choline chloride-based deep eutectic solvents in improving the economic viability of lumbang biodiesel as green alternative fuel.
\end{abstract}

Keywords: Lumbang biodiesel, Deep eutectic solvents, Fatty acid methyl ester, Candlenut, Direct acid-base catalysis, Free fatty acids, Spectroscopic analysis.

\section{INTRODUCTION}

The demand for fuel energy is increasing at a faster rate due to increasing population and rapid industrialization in some countries of the world ${ }^{1,2}$.
The increasing utility of nonrenewable fossil fuel has led to the increase not only in the cost of the fuel but also in the release of carbon particulates that cause global temperature to rise $^{3}$. This worldwide problem on fossil fuel depletion and environmental

This is an Open Access article licensed under a Creative Commons license: Attribution 4.0 International (CC- BY). Published by Oriental Scientific Publishing Company @ 2018

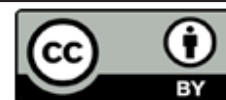


contamination has encouraged scientists to search for fuel alternative that is renewable, environmentally benign, and cost-effective ${ }^{4}$. Biodiesel is one of the fuel alternatives that has been considered due to its close similarity to petroleum diesel combustion properties ${ }^{5}$ but has the advantages of being less toxic, biodegradable, and renewable ${ }^{6}$. Biodiesel has low COx and SOx emissions than petroleum diesel because it is more oxygenated and contains less sulfur than petroleum-based fuel ${ }^{7,8}$. This renewable energy source is produced by transesterification of a triglyceride such as vegetable oil or animal fat with a short chain alcohol (methanol or ethanol) in the presence of an acid, base, or enzyme catalyst $t^{9,10}$. Early researches on biodiesel feedstocks focused on the oil extracted from plants such as rapeseed ${ }^{11}$, soybean ${ }^{12}$, and coconut oil ${ }^{13}$ but because of food versus energy issue ${ }^{14}$, attention is now directed towards the use of second generation biofeedstock such as algae ${ }^{15}$, jatropha ${ }^{16}$, rubber seeds ${ }^{17}$, and other non-edible oil sources ${ }^{18,19}$. The competitive nature of biodiesel against petroleum-based diesel is usually limited by the nature of feedstock, synthetic process, and biodiesel purification technique ${ }^{17,20,21}$. The efficiency of biodiesel as a fuel is usually decreased due to the presence of various impurities such as excess reactants, partially hydrolyzed products, water, and glycerol ${ }^{22}$. These unwanted impurities can decrease engine performance and may cause side reactions leading to the production of toxic products such as acrolein and carbon particulates ${ }^{23,24}$. Before a biodiesel can be used commercially, it has to pass the accepted international standards (EN 14214 and ASTM D6751) ${ }^{25}$ for biodiesel; thus, the removal of impurities is of utmost importance. Various methods of biodiesel purification have been employed and it appears that wet washing which utilizes water as the washing agent is highly accessible; however, this process shares a large portion of the production cost and decreases engine performance ${ }^{26}$. The hydrolyzing property of water causes the alkylester or biodiesel to breakdown releasing fatty acids that can corrode the combustion engine.

Recently, a new wave of generation solvents known as ionic liquids (ILs) ${ }^{27}$ and deep eutectic solvents (DESs) ${ }^{28}$ were extensively investigated for various applications. These are ionic substances that exist as liquids at ambient temperature and exhibit several advantages over other solvents such as nonflammability, eco-friendly, and tunable polarity.
DESs are highly favored than ILs because of their less toxic property and environmental compatibility ${ }^{29}$. These new solvent systems contain individual substances with high melting points; however, due to hydrogen bonding interaction ${ }^{30}$, a sudden drop in the melting point of the mixture is observed and with the proper molar ratio of the two components, a liquid phase can be observed at relatively low temperature ${ }^{31}$.

The formation of low temperature liquid mixture is not only restricted to the mixing of two solids with high melting points but DESs can also be formed by the combination of a cationic solid and a liquid with low melting point such as glycerol and ethylene glycol ${ }^{32}$. DES can easily be synthesized with one hundred percent economy by mixing a hydrogen bond acceptor (HBA) like choline chloride with a hydrogen bond donor (HBD) like glycerol and carboxylic acid ${ }^{33}$. In 2007, Abbott ${ }^{32}$ and his research team, successfully extracted glycerol impurity from biodiesel using choline chloride-glycerol DES. Because DES can interact with both polar and nonpolar components, it is envisaged that maximum removal of impurities from biodiesel can be attained using appropriate DES system. In the present investigation, candlenut (Aleurites moluccana)derived biodiesel was purified using various choline chloride-based DESs. The removal efficiency of DESs was assessed by conducting physicochemical characterization on the purified biodiesel following the accepted international standards on biodiesel. Candlenut is a plant commonly found in tropical regions which can grow as high as $10 \mathrm{~m}$. It is grown domestically as lumbang tree in the Philippines. Lumbang seed can produce $30-60 \%$ nonedible oil ${ }^{34}$ which makes it a potential feedstock for biodiesel production.

\section{MATERIALS AND METHODS}

\section{Materials}

Lumbang seeds were obtained from the College of Forestry, University of the Philippines Los Baños, Laguna. Choline chloride, glycerol, and ethylene glycol which are of analytical grade were purchased from Sigma Aldrich (Singapore). These reagents were dried in a desiccator for $6 \mathrm{~h}$ before being used. Hexane, methanol, $\mathrm{H}_{2} \mathrm{SO}_{4}$, and $\mathrm{NaOH}$ (ACS grade) were obtained from Merck. All chemicals were used without further purification. 


\section{Extraction of Lumbang Oil}

Good quality lumbang seeds were washed and air-dried for $48 \mathrm{~h}$ at room temperature and then cracked to obtain the kernel. The kernels were dried further at $100^{\circ} \mathrm{C}$ for $3 \mathrm{~h}$ before being ground. Lumbang oil was extracted using a Soxhlet apparatus. Twenty-five grams (25 g) of the ground sample was introduced into an extraction tube that was connected to a $250-\mathrm{mL}$ flask containing hexane $(150 \mathrm{~mL})$. The solvent was then heated at its boiling point $\left(68^{\circ} \mathrm{C}\right)$ to extract the oil which lasted for 3 hours. The resulting oil-solvent mixture was filtered and then was subjected to a rotary evaporator at $40^{\circ} \mathrm{C}$ to remove the solvent.

\section{Physicochemical Characterization of Lumbang oil Acid Number and Percent Free Fatty Acid Determination}

Following standard procedure, lumbang oil $(5 \mathrm{~g})$ was mixed with absolute ethanol $(25 \mathrm{~mL})$ and then heated at $65^{\circ} \mathrm{C}$ for 10 minute. After cooling the solution to room temperature, this was titrated with $0.10 \mathrm{M} \mathrm{KOH}$ until phenolphthalein endpoint. The acid number was calculated using equation 1.

Acid Number $=\frac{\mathrm{V}_{\mathrm{KOH}} \times \mathrm{M}_{\mathrm{KOH}} \times \mathrm{MW}_{\mathrm{KOH}}}{\mathrm{W}_{\text {oil }}}$

where $\mathrm{V}_{\mathrm{KOH}}$, the volume of $\mathrm{KOH}(\mathrm{mL})$; $\mathrm{M}_{\mathrm{KOH}}$, the molar concentration of $\mathrm{KOH} ; \mathrm{MW}_{\mathrm{KOH}}$, the molar weight of $\mathrm{KOH}$, and $\mathrm{W}_{\text {oil }}$, the weight $(\mathrm{g})$ of oil sample.

The free fatty acid (FFA) content in lumbang oil was then calculated using equation 2 .

$$
\% \mathrm{FFA}=\mathrm{V}_{\mathrm{KOH}} \times \mathrm{M}_{\mathrm{KOH}} \times \frac{\mathrm{M}}{1000} \times \frac{100}{\mathrm{~W}_{\text {oil }}}
$$

Where $M$ is the average molar weight of fatty acid.

\section{Saponification Number}

A mixture containing $5 \mathrm{~g}$ oil and $25 \mathrm{~mL}$ of $0.5 \mathrm{M}$ alcoholic $\mathrm{KOH}$ was refluxed for $15 \mathrm{~min}$ and then titrated to end point using $0.5 \mathrm{M} \mathrm{HCl}$ and phenolphthalein indicator. The same treatment was done with the blank control which contains $25 \mathrm{~mL}$ of alcoholic $\mathrm{KOH}(0.5 \mathrm{M})$. The saponification number was computed using equation 3 .

Saponification Number $=\frac{\left.\left(\mathrm{V}_{\mathrm{HCl}(\text { lank }}\right)-V_{\mathrm{HCl}(\text { (sample })}\right) \times \mathrm{M}_{\mathrm{HCl}} \times \mathrm{MW}_{\mathrm{KOH}}}{\mathrm{W}_{\text {oil }}}$ where $\mathrm{V}_{(\mathrm{HCl}(\text { blank) })}$, the volume of $\mathrm{HCl}$ required for the blank $(\mathrm{mL}) ; \mathrm{V}_{(\mathrm{HCl}(\text { sample) })}$, the volume of $\mathrm{HCl}$ required for the sample; and $\mathrm{M}_{\mathrm{HCl}}$, the molar concentration of $\mathrm{HCl}$.

\section{lodine Number}

A mixture containing oil $(0.25 \mathrm{~g})$, chloroform $(10 \mathrm{~mL})$, and Wijs solution $(25 \mathrm{~mL})$ was introduced into a 250-mL Erlenmeyer flask, covered, and mixed continuously for 30 minure. The resulting solution was charged with $30 \% \mathrm{KI}(10 \mathrm{~mL})$ and water $(100 \mathrm{~mL})$ and then titrated with $0.1 \mathrm{M} \mathrm{Na}_{2} \mathrm{~S}_{2} \mathrm{O}_{3}$ to endpoint using starch as indicator. For the blank control, the same procedure was performed but without the oil sample. The iodine number was computed using equation 4.

$$
\text { lodine Number }=\frac{\left(\mathrm{V}_{\mathrm{Na}_{2} \mathrm{~S}_{2} \mathrm{O}_{3}(\text { blank })}-\mathrm{V}_{\left.\mathrm{Na}_{2} \mathrm{~S}_{2} \mathrm{O}_{3} \text { (sample }\right)}\right) \times \mathrm{N}_{\mathrm{Na}_{2} \mathrm{~S}_{2} \mathrm{O}_{3}} \times \mathrm{MW}_{\text {iodine }}}{\mathrm{W}_{\text {oil }}}
$$

where $\mathrm{V}_{\mathrm{Na2S2O} \text { (blank) }}$ the volume $(\mathrm{mL})$ of $\mathrm{Na}_{2} \mathrm{~S}_{2} \mathrm{O}_{3}$ required for the blank; $\mathrm{V}_{\mathrm{Na2S2O} \text { (sample) }}$, the volume (mL) of $\mathrm{Na}_{2} \mathrm{~S}_{2} \mathrm{O}_{3}$ required for the sample; $\mathrm{M}_{(\mathrm{Na2S2O3})}$, the molar concentration of $\mathrm{Na}_{2} \mathrm{~S}_{2} \mathrm{O}_{3}$; and $\mathrm{MW}_{\text {iodine }}$, the molar weight of iodine.

\section{Density}

Density of the oil was determined according to literature procedure ${ }^{36}$. An empty 50-mL pycnometer (oven dried) was weighed before it was filled up with water and weighed again at room temperature. The same process was done for the oil sample and the density of the oil was calculated using equation 5 .

$\rho=(W o-W p) /(W w-W p)$

Where Wo, is the weight $(\mathrm{g})$ of the oil; $\mathrm{Wp}$, the weight ( $\mathrm{g}$ ) of the pycnometer; Ww, the weight $(\mathrm{g})$ of the water.

\section{Viscosity}

A volume of $5 \mathrm{~mL}$ distilled water was transferred to an Oswald viscometer and maintained at room temperature. The liquid was then drawn to a point above the upper graduation on the smaller arm and allowed to flow down. The time required for the liquid to pass from the upper mark to the lower mark was recorded and 10 readings were obtained. The same steps were done using the oil sample. The viscosity $\left({ }^{\eta}\right)$ of oil at temperature $T$ was calculated using equation 6 . 


$$
\frac{{ }^{\eta} \text { oil }}{{ }^{\eta_{\text {water }}}}=\frac{\rho_{\text {oil }} \times T_{\text {oil }}}{\rho_{\text {water }} \times T_{\text {water }}}
$$

Where "oil, is the viscosity of the oil; " ${ }_{\text {water? }}$ the viscosity of the water; $\rho_{\text {oil }}$, the density of the oil; $\rho_{\text {water }}$, the density of the water; $T_{\text {oil }}$, the temperature of the oil; and $T_{\text {water }}$, the temperature of the water.

\section{Direct Acid-Base Catalyzed Synthesis of Candlenut Biodiesel}

One hundred grams (100 g) of lumbang oil amended with $0.7 \mathrm{~g}$ concentrated $\mathrm{H}_{2} \mathrm{SO}_{4}$ and $25 \mathrm{~mL}$ of methanol was introduced into a $250-\mathrm{mL}$ distilling flask which was attached to a reflux condenser. The mixture was heated $\left(65^{\circ} \mathrm{C}\right)$ and continuously mixed (400 rpm) for 2 hours. The partially esterified lumbang oil was cooled to room temperature and the acid catalyst was neutralized with $\mathrm{NaOH}$. The mixture was charged with alcoholic methanol $(0.5 \mathrm{~g} \mathrm{NaOH} / 25 \mathrm{~mL} \mathrm{MeOH})$ and then heated and mixed for another 2 hour. The resulting product was cooled to room temperature and was transferred to a separatory funnel and allowed to stand overnight to separate crude glycerol and biodiesel.

\section{DESs Synthesis and Biodiesel Purification}

Three choline chloride $(\mathrm{ChCl})$-based DESs were prepared using glycerol and ethylene glycol as hydrogen bond donors. These were prepared in three different molar ratios; 1:2 choline chloride:glycerol (ChCl:Gly), 1:2 choline chloride:ethylene glycol ( $\mathrm{ChCl:Eg}$ ) and 1:2:2 choline chloride:glycerol:ethylene glycol (ChCl:Gly:Eg). Each solvent system was placed in a flask and stirred (300 rpm) while heated at $80^{\circ} \mathrm{C}$ until a clear mixture was formed. The formation of DES was confirmed by ${ }^{1} \mathrm{H}$ NMR analysis. Each synthesized DES was added to the biodiesel in two DES:biodiesel molar ratios of $1: 1$ and 2:1. Extraction was done by stirring the solution at $30^{\circ} \mathrm{C}$ for 4 hour. The resulting solution was allowed to settle for $2 \mathrm{~h}$ to separate the DES from the biodiesel layer. The purified biodiesel was subjected to different physicochemical analysis.

\section{${ }^{1} \mathrm{H}$ NMR Analysis of DESs}

${ }^{1} \mathrm{H}$ NMR spectra were recorded on a Bruker AVANCE II spectrometer operating at 300 $\mathrm{MHz}$. Chemical shifts were reported in ppm with the solvent resonance $\left(\mathrm{D}_{2} \mathrm{O}\right)$ as the internal standard.

\section{FTIR Analysis of Lumbang-Derived Biodiesel}

A drop of sample was placed between $\mathrm{KBr}$ plates clamped and scanned from $4000 \mathrm{~cm}^{-1}$ $-500 \mathrm{~cm}^{-1}$ to obtain an FTIR spectrum (Thermo Scientific Nicolet 6700 FTIR).

\section{Physicochemical Characterization of Candlenut Biodiesel}

Characterization of DES-purified and unpurified biodiesel was done at the Department of Energy according to the accepted international standard methods: FAME (EN 14214, Shimadzu GC-2014); total glycerin and unreacted triglycerides (EN 14105, Shimadzu GC-2014) and kinematic viscosity (ASTM D445, Koehler ${ }^{\mathrm{TM}}$ Instrument KV5000).

\section{RESULTS AND DISCUSSION}

Candlenut (Aleurites moluccana), also known as lumbang in the Philippines, is a tree that grows favorably in tropical regions. The plant seed contains a considerable amount of non-edible oil which can be a potential feedstock for biodiesel (Fig. 1). However, one major disadvantage of using biodiesel is the recurrence of impurities ${ }^{24}$ which lower fuel efficiency. In this study, lumbang biodiesel was synthesized and purified using the three DESs and the purified biodiesel was characterized according to the accepted international standards (ASTM D6751; EN 14214).
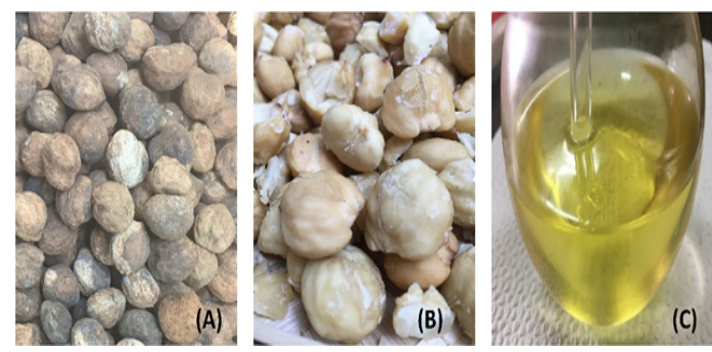

Fig. 1. Lumbang seeds (A), kernels (B), and lumbang oil (C)

\section{Characterization of Lumbang Crude Oil}

Preliminary assessment on the properties of lumbang oil is shown in Table 1. The golden yellow color of lumbang oil (Fig. 1) which yielded about $56 \%$ of oil, considerably higher than other sources of biofeedstock ${ }^{11,37}$, has an enormous viability as a fossil fuel alternative. 
Table 1: Physicochemical properties of lumbang crude oil

\begin{tabular}{lc}
\hline Property & Experimental Value \\
\hline Density $(\mathrm{g} / \mathrm{mL})$ & 0.9271 \\
$\mathrm{pH}$ & 5.13 \\
lodine number $\left(\mathrm{g} \mathrm{I}_{2} / 100 \mathrm{~g}\right.$ oil) & 120.50 \\
Moisture (\%wt) & 12.22 \\
Acid No. (mg KOH/g oil) & 11.97 \\
Saponification Number (mg KOH/g oil) & 103.82 \\
Free Fatty Acid (\%) & 6.52 \\
Viscosity (mm²/s) & 27.34 \\
\hline
\end{tabular}

The density of the oil $(0.9271 \mathrm{~g} / \mathrm{mL})$ which is within the biodiesel standard value $(0.860-0.900)^{5}$ is a very important property to consider in assessing injection pump condition. High density oil produces biodiesel that could damage the injection pump system. In addition, biodiesel with high density would lead to incomplete combustion and accumulation of carbon particulates in the atmosphere ${ }^{38}$. Lumbang oil has a viscosity of $27.34 \mathrm{~mm}^{2} / \mathrm{s}$ which is relatively low compared to other common biofeedstocks ${ }^{39}$ but with comparable densities. Viscosity, which measures the fluidity of fuel, is one of the important parameters that is assessed as this would lower the efficiency of the injection pipeline of the combustion engine ${ }^{40}$. The increase in the number of double bonds, which is assessed by measuring the iodine number, decreases the viscosity of an oil ${ }^{41}$. The iodine number of lumbang oil was $120.50\left(\mathrm{gl}_{2} / 100\right.$ $\mathrm{g}$ oil) close to the accepted standard value of 120 for biodiesel (EN 14214). In other investigations, candlenut oil was reported to have an iodine number which ranges from 130-140 ( $\mathrm{gl}_{2} / 100 \mathrm{~g}$ oil) classifying it as a semi-drying oil ${ }^{5}$. Environmental factors such as seasonal variation, geographical location, and soil conditions may affect oil compositions of feedstock ${ }^{42}$. An increase in iodine number which accounts for the presence of double bonds in the fatty acid component of the triglyceride has a negative effect on the oxidation stability of the biodiesel; however, this could lower the pour point and cloud point temperature of the fuel ${ }^{43}$. One disadvantage of biodiesel is its high viscosity which increases at lower temperature, but this can be remedied through the use of additives or blending it with petrodiese $\left.\right|^{40}$.

The $\mathrm{pH}$ value of the oil was slightly acidic (5.13) which was reflected in the higher acid value (11.97) and \%FFA (6.52) that were obtained. As shown in Table 1, lumbang exhibited a saponification value of $103.82 \mathrm{mg} \mathrm{KOH} / \mathrm{g}$ oil and a moisture content of $12.22 \%$ wt.; pertinent properties that affect the percentage yield of biodiesel during synthesis. Oil with high moisture content, \%FFA, and high saponification value has the possibility to form emulsion due to soap formation thus decreasing the ease of separation and the yield of biodiese $\left.\right|^{4-46}$.

\section{Candlenut Biodiesel Synthesis and DESs Purification}

Preliminary assessment of the oil showed that candlenut oil has high fatty acid content and this would delimit the synthesis of biodiesel especially if the reaction is catalyzed by a base because it would lead to soap formation and thus lowering the yield of biodiesel. Acid-catalyzed reaction is not affected by the free fatty acid content of the oil; however, the reaction has its own downstream due to the reversibility of the reaction and longer reaction time ${ }^{47}$. Although there are other methods of biodiesel syntheses, these processes are either energy extensive, costly, or time consuming ${ }^{48}$. Recently, a direct method of acid-base catalyzed transesterification reaction has shown promise in generating biodiesel with high yield ${ }^{49}$. A similar synthetic strategy was utilized in this investigation yielding $92.31 \%$ crude biodiesel for an oil:methanol ratio of $4: 1(\mathrm{~m} / \mathrm{v})$ containing $0.7 \% \mathrm{wt}$. $\mathrm{H}_{2} \mathrm{SO}_{4}$ in the acid-catalyzed step and oil:methanol ratio of $4: 1(\mathrm{~m} / \mathrm{v})$ containing $0.5 \%$ wt. $\mathrm{NaOH}$ for the base-catalyzed step.

Synthesis of biodiesel involves the sequential transesterification of triglyceride (oil) with alcohol of which methanol is commonly used in the presence of an acid or base catalyst or a combination of both to finally produce a mixture of alkylesters and glycerol (Fig. 2). However, due to reaction limitation, byproducts such as water, glycerol, partially hydrolyzed oil, alcohol, and catalyst can be integrated in the biodiesel layer causing the efficiency of the biodiesel to drop. Different DESs were prepared to remove these impurities as shown in Table 2.

Table 2: Molar ratios of Deep Eutectic Solvents (DESs) and DES-biodiesel phase systems

\begin{tabular}{lccc}
\hline DES Composition & $\begin{array}{r}\text { DES Label } \\
\text { Molar Ratio }\end{array}$ & DES & $\begin{array}{r}\text { DES:Biodiesel } \\
\text { Molar Ratio }\end{array}$ \\
\hline $\mathrm{ChCl}:$ Gly & DES1-11 & $1: 2$ & $1: 1$ \\
$\mathrm{ChCl}:$ Gly & DES1-21 & $1: 2$ & $2: 1$ \\
$\mathrm{ChCl}:$ Eg & DES2-11 & $1: 2$ & $1: 1$ \\
$\mathrm{ChCl}:$ Eg & DES2-21 & $1: 2$ & $2: 1$ \\
$\mathrm{ChCl}: \mathrm{Gly}: \mathrm{Eg}$ & DES3-11 & $1: 2: 2$ & $1: 1$ \\
$\mathrm{ChCl}:$ Gly : Eg & DES3-21 & $1: 2: 2$ & $2: 1$ \\
\hline
\end{tabular}

$\mathrm{ChCl}=$ choline chloride; $\mathrm{Gly}=$ glycerol $\mathrm{Eg}=$ ethylene glycol 


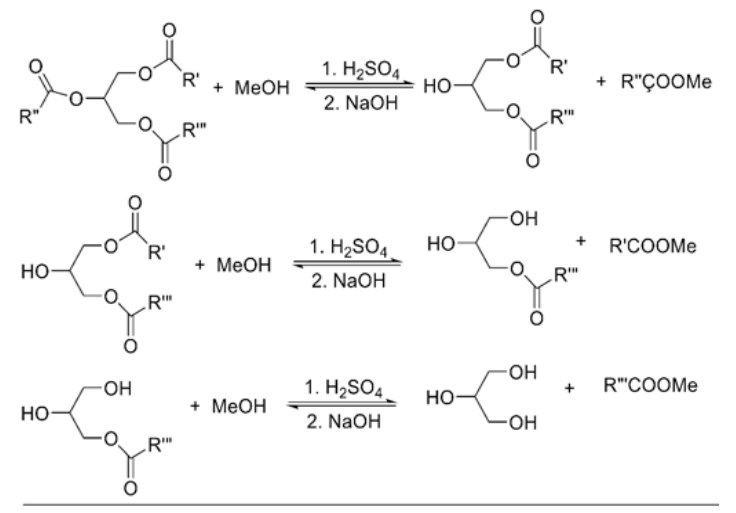

等"

Fig. 2. Transesterification of triglyceride by direct acid-based catalyzed reaction

DES synthesis basically involves mixing of a hydrogen bond acceptor (HBA) with a hydrogen bond donor (HBD) to form a clear and homogeneous liquid. In this study, choline chloride $(\mathrm{ChCl})$ was used as HBA with glycerol (Gly) and ethylene glycol (Eg) as HBD. All mixtures remained opaque for the first few minutes of stirring and from a gel-like appearance, started to become clear after $10 \mathrm{~min}$ (Fig. 3). A clear colorless liquid was obtained after approximately 15 min of continuous stirring at a constant temperature of $80^{\circ} \mathrm{C}$.

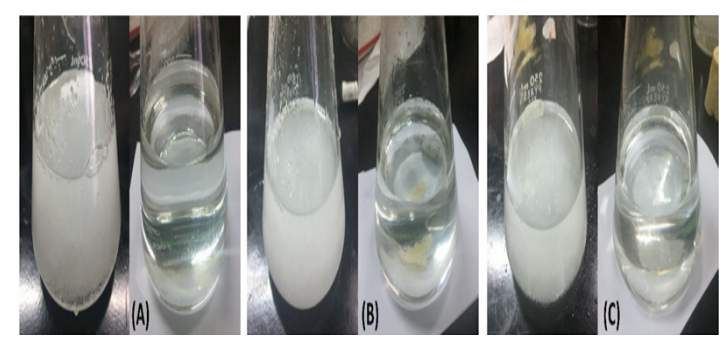

Fig. 3. Synthesis of DESs in different molar ratios: (A) ChCl:Gly, 1:2; (B) ChCl:Eg, 1:2; (C) ChCl:Gly:Eg, 1:2:2

The synthesis of the different DESs was confirmed by ${ }^{1} \mathrm{H}$ NMR analysis (Bruker Avance, $300 \mathrm{MHz}$ ). The ${ }^{1} \mathrm{H}$ NMR spectra of choline chloride, glycerol, and the choline chloride-glycerol DES are depicted in Fig. 4. A singlet peak was observed at $4.790 \mathrm{ppm}$ due to the formation of HOD from the exchange of the hydroxyl protons with $\mathrm{D}_{2} \mathrm{O}$. The spectrum of $\mathrm{ChCl}$ revealed a quartet signal at 4.0295 ppm arising from the methylene proton attached to the hydroxyl group. A triplet signal was observed at
3.487 ppm due to the presence of the neighboring methylene proton, whereas a singlet at $3.169 \mathrm{ppm}$ was attributed to the equivalent resonance of the three methyl protons. Glycerol displayed a quintet proton resonance centered at 3.736 which accounts for the four methylene protons. The magnetic nonequivalence of methylene protons appeared at 3.607 and 3.524 ppm. A singlet peak was observed for ethylene glycol centered at $3.636 \mathrm{ppm}$. The chemical shift in ${ }^{1} \mathrm{H}$ NMR of DES1-11 (ChCl/Gly) appeared at $\delta 4.041$ (quartet), 3.754 (quintet), 3.626 (double of doublet), 3.522 (quintet), and 3.187 (singlet) ppm. An overlap was observed between the triplet proton peak of $\mathrm{ChCl}$ and the quintet (3.522 ppm) proton peak of glycerol. The characteristic methylene peak of $\mathrm{ChCl}$ shifted from $4.0295 \mathrm{ppm}$ to $4.041 \mathrm{ppm}$ whereas the methyl nitrogen peak shifted from $3.169 \mathrm{ppm}$ to $3.187 \mathrm{ppm}$. The methine proton of Gly shifted from 3.736 to 3.754 while the methylene proton shifted from $3.607 \mathrm{ppm}$ to $3.626 \mathrm{ppm}$. The shifting of the peaks downfield can be attributed to hydrogen bond interactions between the hydrogen bond acceptor and the hydrogen bond donor ${ }^{50}$.

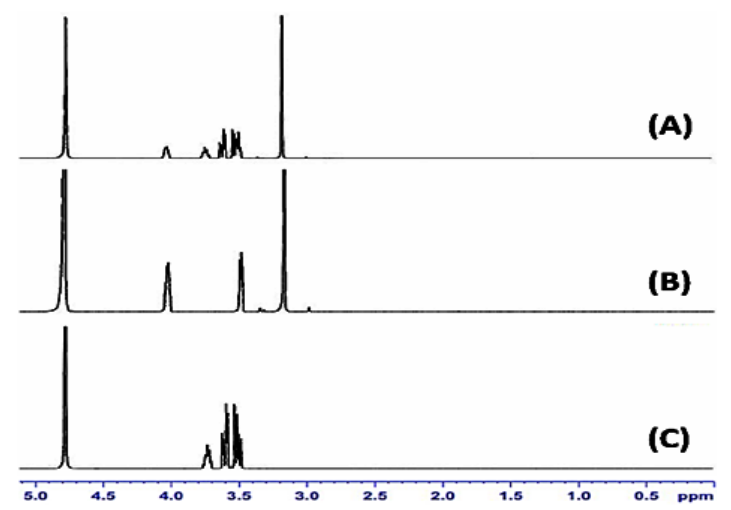

Fig. 4. ' $1 \mathrm{H}$ NMR spectra of (A) ChCl/Gly DES, (B) $\mathrm{ChCl}$, and (C) Gly in deuterated water

\section{Assessment of DESs Purified and Unpurified} Biodiesel

The potency of the different DESs in purifying lumbang biodiesel was assessed by conducting physicochemical characterization of the DES-purified and unpurified biodiesel. Extraction of impurities from crude biodiesel was performed using the three DES systems; two binary systems (ChCl:Gly, 1:2; ChCl:Eg, 1:2) and one ternary system (ChCl:Gly:Eg, 1:2:2). Biodiesel was purified with the different DESs by preparing DES:biodiesel mixtures with molar ratios of $1: 1$ and 1:2. Fig. 5 presents the extraction profiles of ChCl-Gly DES:biodiesel system. 
After $4 \mathrm{~h}$ of mixing $(400 \mathrm{rpm})$ at $30^{\circ} \mathrm{C}$, and of $2 \mathrm{~h}$ settling time, one would notice the DES layer became turbid indicating the removal of some impurities possibly due to polar interaction with DES51.
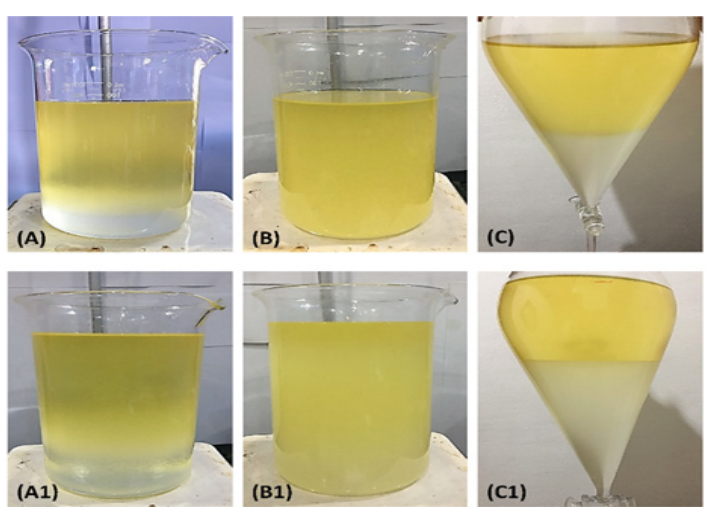

Fig. 5. Purification of biodiesel with ChCl/Gly DES in $1: 1$ (top) and 2:1 (bottom) DES:biodiesel molar ratios: A, A1 (before mixing); B, B1 (after mixing, 4 h); and C, C1 (after settling, 2 h)
Upon rotary evaporation, it was found that all samples still have residual methanol, the volumes of which are recorded in Table 3 ; however, it can be noted that the volume of methanol collected from the unpurified biodiesel was significantly higher than that collected from the DES-purified biodiesel samples. These results show the effectiveness of DESs in extracting polar impurity such as methanol.

FTIR analysis of the purified and unpurified biodiesel revealed a large decrease in the intensity of the hydroxyl peak $\left(3500 \mathrm{~cm}^{-1}-3400 \mathrm{~cm}^{-1}\right)$ indicating that hydroxyl containing impurities such as water, methanol, and partially hydrolyzed oil may have been removed from the unpurified diesel (Fig. 6b). The FTIR spectrum of purified lumbang biodiesel (Fig.6a) aligns with the candlenut spectrum of Imdadul et $a^{\mu 3}$. Important peaks accounting for fatty acyl methyl ester, $-\mathrm{C}=\mathrm{O}$ and $-\mathrm{C}-\mathrm{O}$ stretches appeared at $1743.32 \mathrm{~cm}^{-1}$ and $1245.04 \mathrm{~cm}^{-1}$, respectively. Moreover, both symmetrical and asymmetrical $\mathrm{CH}_{2}$ stretches appeared at $3000 \mathrm{~cm}^{-1}$.

Table 3: Volume of methanol removed under vacuum in purified and unpurified biodiesel

\begin{tabular}{lccccccc}
\hline & Unpurified & DES1 & Purified & DES2 & Purified & DES3 & Purified \\
\hline DES:Biodiesel (molar ratio) & - & $1: 1$ & $2: 1$ & $1: 1$ & $2: 1$ & $1: 1$ & $2: 1$ \\
Methanol $(\mathrm{mL})$ & 6.10 & 0.10 & 0.10 & 0.11 & 0.12 & 0.11 & 0.10 \\
\hline
\end{tabular}

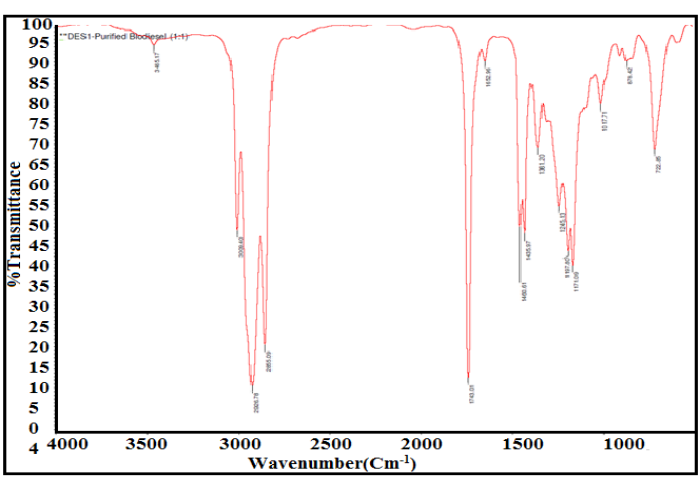

Fig. 6a. FTIR profile of DES-purified biodiesel (DES system, Chl:Gly, 1:1)

Stretching frequency of $-\mathrm{OH}$ group in unpurified biodiesel (Fig. 6B) which can be attributed to water, excess methanol, and partially hydrolyzed triglyceride was observed at $3400 \mathrm{~cm}^{-1}$. It can be noted that the peak at $\sim 1430 \mathrm{~cm}^{-1}$ arising from deformation vibrations of methyl ester ${ }^{35}$ and the peak at $\sim 1200 \mathrm{~cm}^{-1}$ corresponding to methoxy stretching vibrations are frequently observed in methyl ester (biodiesel) but not in its corresponding triglyceride ${ }^{52}$. This difference proves the effective

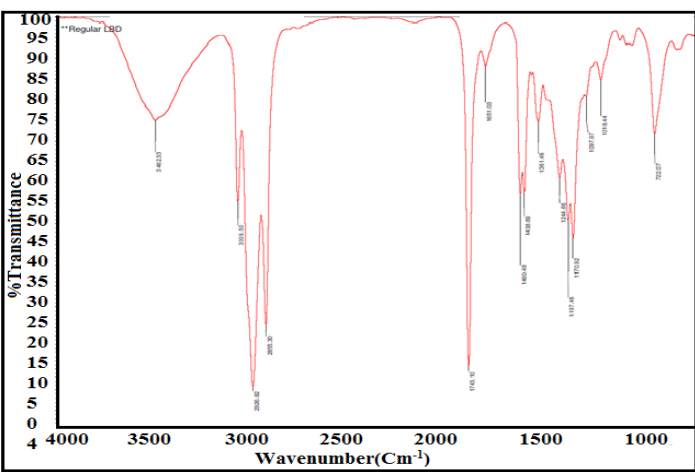

Fig. 6b. FTIR profile of unpurified biodiesel (DES system Chl:Gly, 1:1)

conversion of triglycerides to methyl esters during transesterification.

\section{Effect of DES on Fatty Acid Methyl Ester (FAME) Content of Lumbang Biodiesel}

Purified and unpurified biodiesel were subjected to other physicochemical analysis using the standard methods (EN 14214; ASTM D6751). Fig. 7 shows the FAME profiles of purified and unpurified biodiesel in different DESs. For a biodiesel to be commercially viable, it should contain a 
minimum FAME value of $96.5 \%$ (EN 14214). Relative to unpurified biodiesel, FAME recovery significantly increased in DES1 (ChCl:Gly) with values of $90.47 \%$ (DES:biodiesel ratio, 1:1) and 89\% (DES:biodiesel ratio, 2:1). The solvent system DES2 (ChCl:Eg) also exhibited a similar result but with a higher FAME content of $98.13 \%$ (DES:biodiesel, $1: 1$ ) and $92.47 \%$ (DES:biodiesel, 2:1). However, for the ternary DES3 system, only the 1:1, DES-biodiesel ratio exhibited an increase relative to the unpurified biodiesel.

Overall, there is a significant increase in FAME in all the DES systems except DES3 with DES:biodiesel ratio of 2:1. Even though there is an increase in FAME content of the purified biodiesel, only DES2 (ChCl:Eg) with DES: biodiesel ratio of 1:1 has surpassed the standard limit set for FAME which is $96.5 \% 25$. In the work of Niawante et al.,${ }^{51} \mathrm{a}$ FAME content of $96.60 \%$ was obtained using choline chloride:ethylene glycol DES (1:2) and DES:biodiesel ratio of 4:1 with an extraction time of $240 \mathrm{~min}$.

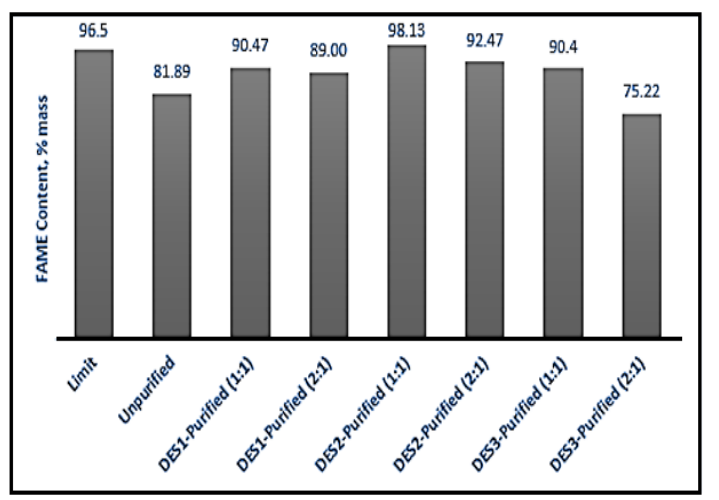

Fig. 7. FAME content of unpurified and purified lumbang biodiesel

\section{Influence of DESs on the Glycerin Content of Lumbang Biodiesel}

In the synthesis of alkyl ester or biodiesel, the reaction does not usually proceed to completion especially under acid catalyzed reaction because of the reversibility of the process ${ }^{53}$. This limitation of the acid catalyzed reaction would lead to the contamination of the synthesized biodiesel with bound glycerol and free glycerins ${ }^{54}$. The presence of these contaminants in biodiesel has an environmental repercussion because during combustion, a toxic product is released in the form of acrolein ${ }^{23}$. In addition, this form of contaminant would increase the viscosity of the biodiesel and initiate corrosion of the engine injection system. The international standards on biodiesel set a maximum value of $0.02 \%$ wt. for the free glycerol and $0.24 \%$ wt. for the total glycerol (free and bound glycerol). The free glycerin contents of the analyzed biodiesel samples are shown in Fig. 8. Both unpurified and purified biodiesel have fulfilled the maximum standard limit which is $0.02 \%$ by weight; however, DES3 at both molar ratios (1:1 and 2:1) and DES2 (1:1, DES:biodiesel) were able to reduce the glycerin content of the unpurified biodiesel to $0.01 \%$ by weight. Shabaz et al., ${ }^{54}$ also noticed a higher percentage removal of free glycerin from biodiesel using ethylene glycol as hydrogen bond donor as compared to glycerol. Ethylene glycol with less hydroxy groups than glycerol may have provided a greater volume for the chloride anion of the salt to interact with the glycerol from the biodiesel phase ${ }^{32}$.

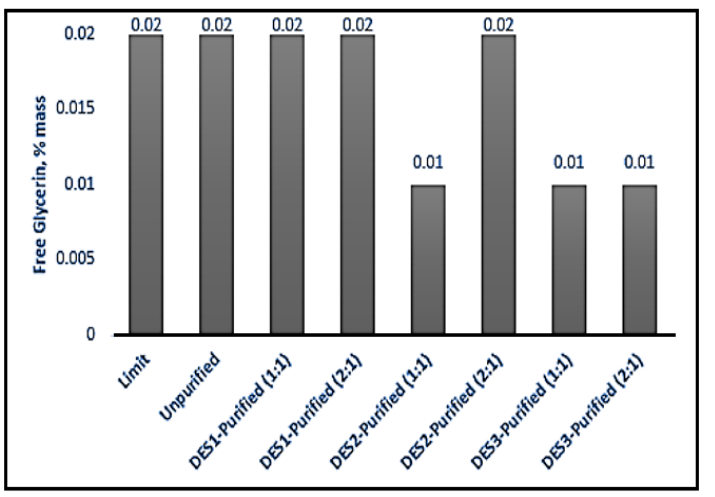

Fig. 8. Free glycerin profiles in purified and unpurified lumbang biodiesel

The total glycerin in unpurified biodiesel was $0.53 \%$ by mass (Fig. 9), which surpassed the standard limit of $0.24 \%$ (EN 14214). Total glycerin accounts for the free and bound glycerins ${ }^{54}$. All DESs significantly reduced the total glycerin in the unpurified sample, with DES1-21 and DES2-11 removing the highest amount $(0.47 \%$ by mass) and having an extraction efficiency of $88.68 \%$. The total glycerin content in all purified samples is below the standard limit except in DES3-21 purified biodiesel which has the lowest extraction efficiency $(41.51 \%)$. Niawanti et al. ${ }^{51}$ noticed an increase in the FAME content of biodiesel as the total glycerides decreased upon extraction with choline chloride-ethylene glycol DES (1:2) with a biodiesel-DES molar ratio of $1: 2$ and $1: 4$. In the study conducted my Ho et al., ${ }^{55}$, the complete removal of triglycerides from biodiesel using ternary systems was mostly unsuccessful. The group reasoned out that the decrease in the removal efficiency can be attributed to either mass transfer or desorption phenomena ${ }^{54}$. 


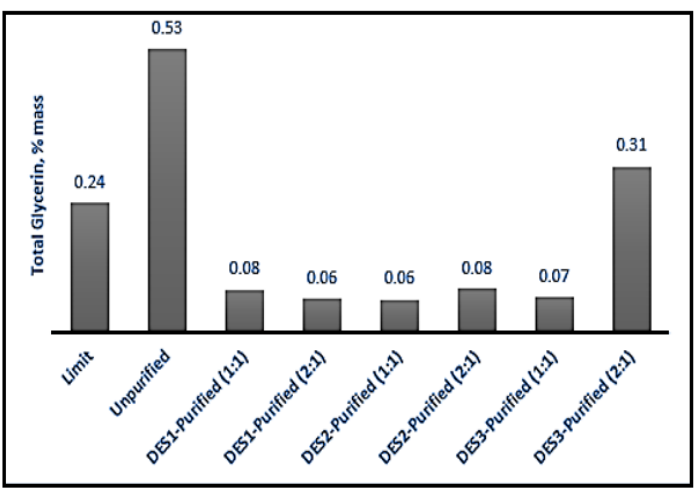

Fig. 9. Total glycerin profiles in purified and unpurified lumbang biodiese

For the monoglyceride and diglyceride contents, both purified and unpurified biodiesel conform to the standard values which are 0.8 and 0.2 , respectively (ASTM D6584-17) ${ }^{56}$; however, one would notice a minimal removal of monoglycerides (Fig. 10) relative to the unpurified biodiesel in all DESs. In contrast to the monoglycerides, the removal of diglycerides by the different DESs was more efficient. Except for DES1-11, which exhibited a removal efficiency of $33 \%$, all other DESs were able to extract about $67 \%$ of the diglyceride from the unpurified biodiesel (Fig. 11). Conversely, as shown in Fig. 12, a high triglyceride content was detected in unpurified biodiesel. Extraction with DES was able to significantly decrease triglyceride content and only DES3-21 failed to reduce the triglycerides below the maximum standard limit. The highest triglyceride removal was observed with DES1 and DES2 at both molar ratios with almost complete removal of the unreacted triglyceride (99.93\%).

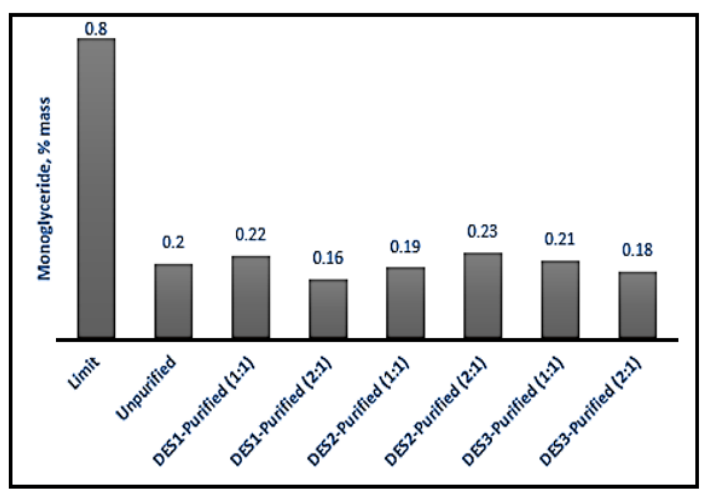

Fig. 10. Percent by mass of monoglycerides in purified and unpurified lumbang biodiesel

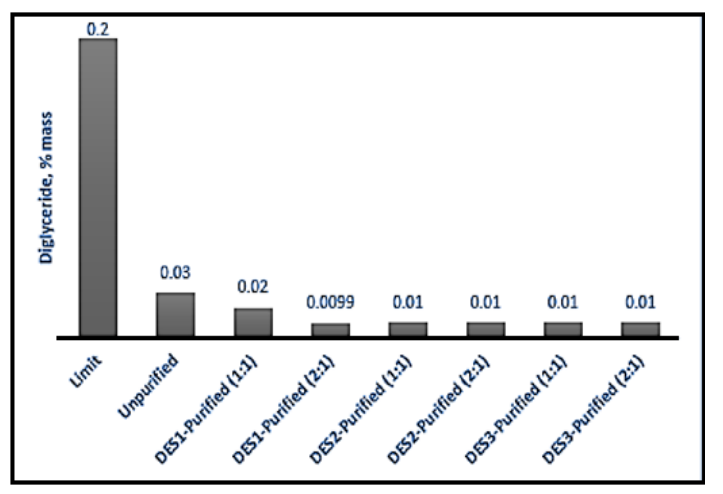

Fig. 11. Percent by mass of diglycerides in purified and unpurified lumbang biodiesel

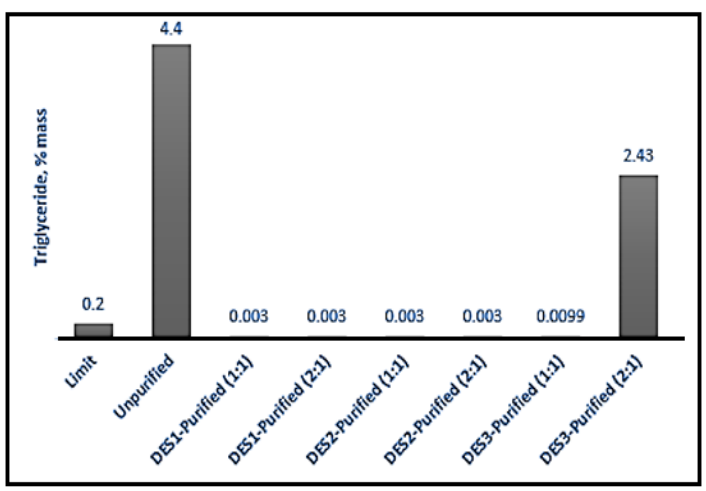

Fig. 12. Percent by mass of triglycerides in purified and unpurified lumbang biodiesel

\section{Effect of DESs on the Viscosity of Lumbang Biodiesel}

From Fig. 13 one would notice a decrease in viscosity of all the DESs-purified biodiesel relative to the unpurified biodiesel from $8-18 \%$. Viscosity is a vital thermo-physical property of biodiesel since it affects engine performance especially during injection and atomization ${ }^{57}$.

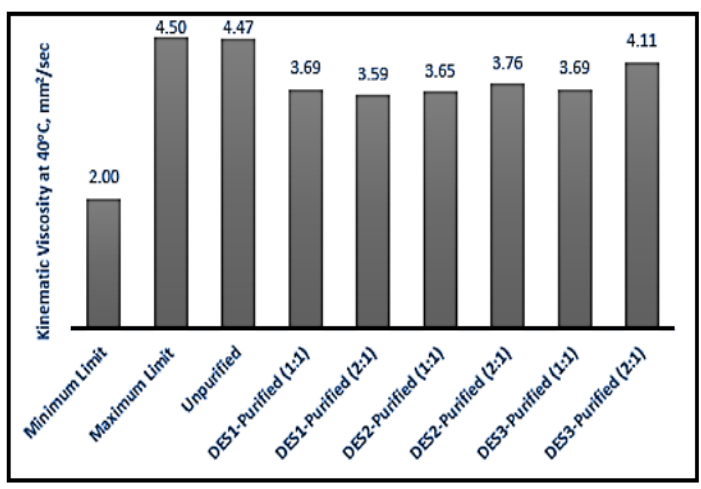

Fig. 13. Effect of DESs on the kinematic viscosity of lumbang biodiesel 
Preliminary analysis of the lumbang oil showed a viscosity of $27.34 \mathrm{~mm}^{2} / \mathrm{s}$ which greatly surpassed the standard limit $\left(2-6 \mathrm{~mm}^{2} / \mathrm{s}\right.$, ASTM 6751-02) $)^{58}$; one reason why oil cannot be used directly as a fuel. However, esterification of the oil reduced the viscosity to about $87 \%$ when DESs were used. Viscosity property is greatly affected by several factors such as temperature, molecular weight, and iodine number. Biodiesel has a relatively higher viscosity than petroleum diesel because of its high molecular weight; but an increase in the number of double bonds in oil decreases the viscosity of the biofeedstock. Lumbang has the advantage over other biofeedstock sources because it contains semi-dry oil that has intermediate viscosity; however, the presence of unsaturated double bonds may lower the oxidation stability of biodiesel.

\section{CONCLUSION}

The viability of the different DESs in enhancing the purity of lumbang biodiesel is demonstrated in this investigation. Biodiesel impurities such as alcohol, and free and bound glycerins have been reduced to a level that fulfilled the standard limit for biodiesel. The removal of impurities has enhanced the physicochemical properties of lumbang biodiesel with an increase in FAME content and a decrease in kinematic viscosity; pertinent properties which measure the commercial viability of the biodiesel. Overall, the binary DES derived from choline chloride-ethylene glycol, with a molar ratio of $1: 2$ and a $\mathrm{DES}$ :biodiesel molar ratio of 1:1 exhibited the highest extraction performance. This study has demonstrated the use of this new generation solvent which embodies the concept of green chemistry can improve the economic potential of a biodiesel as an alternative fuel.

\section{ACKNOWLEDGMENT}

This work was funded by the UP System Enhanced Creative Work and Research Grant (ECWRG-2018-1-015).

\section{Conflict of interest}

The authors declare that there is no conflict of interest.

\section{REFERENCES}

1. Fischer-Kowalski, M.; Swilling, M.; von Weizsäcker, E.U.; Ren, Y.; Moriguchi, Y.; Crane, W.; Krausmann, F.; Eisenmenger, N.; Giljum, S.; Hennicke, P.; Romero Lankao, P.; Siriban Manalang, A. Decoupling natural resource use and environmental impacts from economic growth, a report of the Working Group on Decoupling to the International Resource Panel. UNEP., 2011.

2. Energy, OECD Green growth studies, OECD Publishing., 2012. http://dx.doi. org/10.1787/9789264115118-en.

3. Shindell, D. T. The social cost of atmospheric release. Climatic Change., 2015, 130, 313-326.

4. Shahzad, U. The need for renewable energy sources. International Journal of Information Technology and Electrical Engineering., 2015, 4, 16-19.

5. Sulistyo, H.; Rahayu, S.; Winoto, G.; Suardjaja, I.M. Biodiesel production from high iodine number candlenut oil. Proc. World Acad. Sci. Eng. Technol., 2008, 36, 485-488.

6. Bateni H.; Saraeian A.; Able C. A comprehensive review on biodiesel purification and upgrading. Biofuel Research Journal., 2017, 15, 668-690.
7. Teixeira E.C.; Mattiuzi C.D.; Feltes S.; Wiegand F.; Santana E.R. Estimated atmospheric emissions from biodiesel and characterization of pollutants in the metropolitan area of Porto Alegre-RS. An Acad Bras Cienc., 2012, 84(3), 655-67.

8. Mishra, V.K.; Goswani, R. A review of production, properties, and advantages of biodiesel. Biofuels., 2018, 9, (2), 273-289.

9. Selaimia, R.; Beghiel, A.; Oumeddour, R. The synthesis of biodiesel from vegetable oil. Procedia - Social and Behavioral Sciences., 2015, 195, 1633-1638.

10. Selvaraj, R.; Praveenkumar, R.; Moorthy, I.G. A comprehensive review of biodiesel production methods from various feedstocks, Biofuels., 2019, 10(3), 325-333.

11. Atabani, A. E.; Silitonga, A. S.; Ong, H. C.; Mahlia, T. M. I.; Masjuki, H. H.; Badruddin, I. A.; Fayaz, H. Non-edible vegetable oils: A critical evaluation of oil extraction, fatty acid compositions, biodiesel production, characteristics, engine performance and emissions production. Renewable and Sustainable Energy Reviews., 2013, 18: 211-245. 
12. Colombo, K.; Ender, L.; Santos, M. M.; Chivanga Barros, A. A. Production of biodiesel from soybean oil and methanol, catalyzed by calcium oxide in a recycle reactor. S. Afr. J. Chem. Eng., 2019, 28, 19-25.

13. Maitera, O.N.; Louis, H.; Dass, P.M.; Akakuru, U.O.; Joshua, Y. Production and characterization of biodiesel from coconut extract (Cocos nucifera). WNOFNS., 2017, 9, 62-70.

14. Prasad, S.; Ingle, A. P. Impacts of sustainable biofuels production from biomass. Sustainable Bioenergy., 2019, 327-346.

15. Dickinson, S.; Mientus, M.; Frey, D.; AminiHajibashi, A.; Ozturk, S.; Shaikh, F.; Sengupta, D.; El-Halwagi, M.M. A review of biodiesel production from microalgae. Clean Techn. Environ. Policy., 2016, 19(3), 637-668.

16. Silitonga, A. S.; Masjuki, H. H.; Mahlia, T. M. I.; Ong, H. C.; Atabani, A. E.; Chong, W. T. A global comparative review of biodiesel production from Jatropha curcas using different homogeneous acid and alkaline catalysts: Study of physical and chemical properties. Renew. Sust. Energ. Rev., 2013, 24, 514-533.

17. Satyanarayana, M.; Muraleedharan, C. Comparative studies of biodiesel production from rubber seed oil, coconut oil, and palm oil including thermogravimetric analysis. Energy Sources, Part A: Recovery, Utilization, and Environmental Effects., 2011, 33(10), 925-937.

18. Canoira, L.; Alcantara, R.; Garcia-Martinez, M.J.; Carrasco, J. Biodiesel from Jojoba oilwax: transesterification with methanol and properties as a fuel. Biomass and Bioenergy. 2006, 30, 76-81.

19. Karmee, S.K.; Chadha, A. Preparation of biodiesel from crude oil of Pongamia pinnata, Bioresource Technol., 2005, 96, 1425-1429.

20. Bateni, H.;Saraeian, A.;Able, C.Acomprehensive review on biodiesel purification and upgrading. Biofuel Res. J., 2017, 15, 668-690.

21. Suthar, K.; Dwivedi, A.; Joshipura, M. A review on separation and purification techniques for biodiesel production with special emphasis on Jatropha oil as a feedstock. Asia-Pac. J. Chem. Eng., 2019, 14, 1-19.

22. Atadashi, I.M. Purification of crude biodiesel using dry washing and membrane technologies. Alex. Eng. J., 2015, 54, 1265-1272.
23. Banga, S.; Varshney, P.K. Effect of impurities on performance of biodiesel: A review. J. Sci. Ind. Res., 2010, 69, 575-579.

24. Atadashi, I.M.; Aroua, M.K.; Abdul Aziz, A. High quality biodiesel and its diesel engine application: A review. Renew. Sust. Energ. Rev., 2010, 14, 1999-2008.

25. Rehlund, B. Outlook on standardization of Alternative vehicle fuels. Global, Regional and National level. Bioenergy NoE. IEA/AMF., 2008, 1-59.

26. Stojkovic, I. J.; Stamenkovic, O. S.; Povrenovic, D. S.; Veljkovic, V. B. Purification technologies for crude biodiesel obtained by alkalicatalyzed transesterification. Renew. Sust. Energ. Rev., 2014, 32, 1-15.

27. Ghandi, K. A review of ionic liquids, their limits and applications. Green and Sustainable Chemistry., 2014, 04(01), 44-53.

28. Tomé, L. I. N.; Baião, V.; da Silva, W.; Brett, C. M. A. Deep eutectic solvents for the production and application of new materials. Appl. Mater. Today., 2018, 10, 30-50.

29. Benvenutti, L.; Zielinski, A. A. F.; Ferreira, S. R.S. Which is the best food emerging solvent: IL, DES or NADES? Trends Food Sci. Tech., 2019, 90, 133-146.

30. Ashworth, C.R.; Matthews, R.P.; Welton, T.; Hunt, P.A. Doubly ionic hydrogen bond interactions within the choline chloride-Urea Deep eutectic solvent. Phys. Chem. Chem. Phys., 2016, 18, 18145-18160.

31. Alonso, D. A.; Baeza, A.; Chinchilla, R.; Guillena, G.; Pastor, I. M.; Ramón, D. J. Deep Eutectic Solvents: The Organic Reaction Medium of the Century. Eur. J. Org. Chem., 2016, 4, 612-632.

32. Abbott, A. P.; Cullis, P. M.; Gibson, M. J.; Harris, R. C.; Raven, E. Extraction of glycerol from biodiesel into a eutectic based ionic liquid. Green Chem., 2007, 9(8), 868-872.

33. Smith, E. L.; Abbott, A. P.; Ryder, K. S. deep eutectic solvents (DESs) and their applications. Chem. Rev., 2014, 114(21), 11060-11082.

34. Subroto, E.;Widjojokusumo, E.;Veriansyah, B.; Tjandrawinata, R. R. Supercritical $\mathrm{CO}_{2}$ extraction of candlenut oil: process optimization using Taguchi orthogonal array and physicochemical properties of the oil. J. Food Sci. and Techno., 2017, 54(5), 1286-1292. 
35. Pham, L. N.; Luu, B. V.; Phuoc, H. D.; Le, H. N. T.; Truong, H. T.; Luu, P. D.; Furuta, M.; Imamura, K.; Maeda, Y. Production of biodiesel from candlenut oil using a two-step co-solvent method and evaluation of its gaseous emissions. J. Oleo Sci., 2018, 67(5), 617-626.

36. Ike, E.; Dikko, A.B. Determination of the Arrhenius parameters of mahogany seed oil using viscosity flow data. IJISRT., 2018, 3(2),1007-1015.

37. Martín, C.; Moure, A.; Martín, G.; Carrillo, E.; Domínguez, H.; Parajó, J. C. Fractional characterisation of jatropha, neem, moringa, trisperma, castor and candlenut seeds as potential feedstocks for biodiesel production in Cuba. Biomass and Bioenergy., 2010, 34(4), 533-538.

38. Verma, P., Stevanovic, S., Zare, A., Dwivedi, G., Chu Van, T., Davidson, Morgan Davidson, M.; Rainey, T.; Brown, R.J.; Ristovski, Z. D. (2019). An overview of the influence of biodiesel, alcohols, and various oxygenated additives on the particulate matter emissions from diesel engines. Energies., 2019, 12(10), 1-25.

39. Sahasrabudhe, S. N.; Rodriguez-Martinez, V.; O'Meara, M.; Farkas, B. E. Density, viscosity, and surface tension of five vegetable oils at elevated temperatures: measurement and modeling. Int. J. Food Prop., 2017, 1-17.

40. Hoang, A.T.; Nguyen, V.T. Emission characteristics of a diesel engine fueled with preheated vegetable oil and biodiesel. Philipp. J. Sci., 2017, 146(4), 475-482.

41. Knothe, G. Rapid monitoring of transesterification and assessing biodiesel fuel quality by near-infrared spectroscopy using a fiber-optic probe 1, J. Am. Oil Chem. Soc., 1999, 76, 795-800.

42. Rahman, M.; de Jiménez, M. M. Designer oil crops. Breeding Oilseed Crops for Sustainable Production., 2016, 361-376.

43. Imdadul, H. K.; Zulkifli, N. W. M.; Masjuki, H. H.; Kalam, M. A.; Kamruzzaman, M.; Rashed, M. M. Rashedul, H.K.; Alwi, A. Experimental assessment of non-edible candlenut biodiesel and its blend characteristics as diesel engine fuel. Environ. Sci. and Pollut. Res., 2016, 24(3), 2350-2363.

44. Bouaid, A.; Vázquez, R.; Martinez, M.; Aracil, J. Effect of free fatty acids contents on biodiesel quality. Pilot plant studies. Fuel., 2016, 174, 54-62.

45. Kusdiana, D.; Saka, S. Effects of water on biodiesel fuel production by supercritical methanol treatment. Bioresource Technolog., 2004, 91(3), 289-295.

46. Canakci, M.; Van Gerpen, J. A pilot plant to produce biodiesel from high free fatty acid feedstocks. Transactions of the ASAE., 2003, 46(4), 945-954.

47. Srivastava, A.; Prasad, R. Triglycerides-based diesel fuels. Renew. Sust. Energ. Rev., 2000, 4, 111-133.

48. Girish, C.R. Review of various technologies used for biodiesel production. IJMPERD., 2019, 9, 1379-1392.

49. Yunus Khan, T. M.; Badruddin, I. A.; Ankalgi, R. F.; Badarudin, A.; Hungund, B. S.; Ankalgi, F. R. Biodiesel production by direct transesterification process via sequential use of acid-base catalysis. Arab. J. Sci. Eng., 2018, 1-8.

50. Yao, L.; Grishaev, A.; Cornilescu, G.; Bax, A. The impact of hydrogen bonding on amide $1 \mathrm{H}$ chemical shift anisotropy studied by cross-correlated relaxation and liquid crystal NMR spectroscopy. J. Am. Chem. Soc., 2010, 132(31), 10866-10875.

51. Niawanti, H.; Zullaikah, S.; Rachimoellah, M. Purification of biodiesel by choline chloride based deep eutectic solvent. AIP Conf. Proc., 2017, 1840, 050006-1-050006-7.

52. Rabelo, S.N.; Ferraz, V.P.; Oliveira, L.S.; Franca, A.S. FTIR Analysis for quantification of fatty acid methyl esters in biodiesel produced by microwave-assisted transesterification. Int J. Environ. Sci. Dev., 2015, 6(12), 964-969.

53. Lotero, E.; Liu, Y.; Lopez, D.E.; Suwannakarn, K.; Bruce, D.A.; Goodwin, J.G. Synthesis of biodiesel via acid catalysis. Ind. Eng. Chem. Res., 2005, 44, 5353-5363.

54. Shahbaz, K.; Mjalli, F. S.; Hashim, M. A.; Alnashef, I. M. Using deep eutectic solvents based on methyl triphenyl phosphonium bromide for the removal of glycerol from palmoil-based biodiesel. Energy \& Fuels., 2011, 25(6), 2671-2678.

55. Ho, K.C.; Shahbaz, K.; Rashmi, W.; Mjalli, F.S.; Hashim, M.A.; Alnashef, I.M. Removal of glycerol from palm oil-based biodiesel using new ionic liquids analogues. JESTEC., 2015, 98-111.

56. ASTM D6584-17, Standard test method for determination of total monoglycerides, total diglycerides, total triglycerides, and free and total glycerin in B-100 biodiesel methyl esters by gas chromatography, ASTM International, West Conshohocken, PA, 2017, www.astm.org.

57. Verduzco, L.F.R. Density and viscosity of biodiesel as a function of temperature: empirical models. Renew. Sust. Energ. Rev., 2013, 19, 652-665.

58. Demirbas, A. Progress and recent trends in biodiesel fuels. Energy Convers. Manag., 2009, 50(1), 14-34. 